\title{
VIVARIUM: WISATA EKOSISTEM RAWA BUATAN DI JAKARTA
}

\author{
Angeline $^{1)}$, Diah Anggraini ${ }^{2)}$ \\ 1) Program Studi S1 Arsitektur, Fakultas Teknik, Universitas Tarumanagara, kim.angelinekim@gmail.com \\ 2) Program Studi S1 Arsitektur, Fakultas Teknik, Universitas Tarumanagara, diah_ismono@yahoo.com
}

\begin{abstract}
Abstrak
DKI Jakarta sebagai ibukota negara terdiri dari 5 wilayah dan 1 kabupaten. Jakarta Utara merupakan salah satu wilayah DKI Jakarta yang terkenal akan rawanya. Ekosistem rawa di Jakarta mengalami banyak sekali perubahan dengan seiring waktu bertumbuhnya kota Jakarta. Sebagian besar area rawa yang merupakan dataran rendah tersebut diubah menjadi kawasan permukiman penduduk sehingga berdampak pada terganggunya keseimbangan ekosistem rawa di Jakarta. Maka untuk menjaga kelestarian ekosistem rawa, masyarakat perlu dikenalkan dan diedukasi mengenai ekosistem rawa serta manfaatnya bagi kehidupan mahluk hidup. Langkah yang dapat dilakukan adalah dengan menghadirkan kembali ekosistem rawa dalam bentuk ekosistem buatan (vivarium). Dalam ekosistem buatan ini, masyarakat akan merasakan pengalaman berada dalam ekosistem rawa dan mengenal kehidupan di dalamnya. Dimulai dari flora dan fauna khas rawa hingga kehidupannya. Selain itu, masyarakat dapat mengenal flora dan fauna khas rawa ini dari dekat dan berinteraksi secara langsung. Untuk mewadahi kegiatan-kegiatan tersebut maka dibuatlah proyek Vivarium, Wisata Ekosistem Rawa Buatan di Jakarta ini. Dalam proyek ini akan berisi ekosistem rawa buatan serta fasilitas untuk menunjang edukasi masyarakat mengenai ekosistem rawa. Tulisan ini bertujuan menghasilkan suatu konsep dan rancangan proyek vivarium yang dapat mewadahi kegiatan-kegiatan terkait wisata ekosistem rawa buatan di Jakarta, yang sekaligus dapat menjadi sarana untuk menunjang edukasi masyarakat agar lebih peduli dan tergerak untuk melestarikan ekosistem rawa. Proyek ini diharapkan dapat menjadi suatu karya architourism yang berdampak positif baik dari sisi pelestarian rawa maupun bagi kesejahteraan masyarakat banyak terutama di Jakarta Utara.
\end{abstract}

Kata kunci: ekosistem buatan, ekosistem rawa, Jakarta, wisata.

\begin{abstract}
DKI Jakarta as a capital consist of 5 city section and one district. North Jakarta is one of the city section that known for its swamp. Swamp ecosystem in Jakarta has been through so many changes as the city grows. Most of those swamp has been changed to be a residential and its affect the stability of Jakarta's ecosystem. Therefore, to maintan the sustainability of Jakarta's ecosystem, the society need to be introduce and get a knowledge about Swamp ecosystem and its value for every living things. What can be done is to present swamp ecosystem in artificial way (vivarium). In this artificial ecosystem, the society would feel how it is to be inside a swamp and knows life in it. Start from the typical swamp flora and fauna to their life in it. Other than that, society could understand and interact with the typical swamp flora and fauna. To accommodate these activity, this Vivarium project was made. This project will consist of artificial swamp and its facility to support society education about swamp ecosystem. This paper aims to produce a concept and vivarium project design that could accommodate swamp tourism activities in Jakarta, which at once could be a media that can support society education to make people more care and want to conserve swamp ecosystem. This project is expected to be an architourism work that has a positive effect for the conservation of swamp and for public welfare especially in North Jakarta.
\end{abstract}

Keywords: artificial ecosystem, Jakarta, swamp ecosystem, tourism

\section{PENDAHULUAN}

Tourism Architecture mengartikan bahwa begitu banyak macam fungsi dari arsitektur dalam konteks pariwisata. Architectural Tourism mengarah ke arsitektur sebagai penarik perhatian pariwisata. Architectural Tourism tidak terbatas pada periode masa atau gaya arsitektural 
tertentu. Karenanya, pariwisata berdedikasi terhadap bentuk arsitektur dari apa yang bisa diartikan sebagai monument bersejarah hingga struktur kontemporer. Architectural Tourism dan Architourism dalam pengertian yang sempit adalah arsitektur sebagai penarik perhatian dari tujuan atau sebagai tujuan tersebut.

Dalam konteks kota metropolis, sebuah kota besar yang merupakan pusat ekonomi, politik, dan budaya yang signifikan untuk suatu negara atau wilayah, dan pusat penting untuk regional atau internasional, maka yang dapat diamati adalah perubahan ekosistem yang terjadi akibat pertumbuhan kota tersebut. Seiring dengan berkembangnya kota Jakarta sebagai kota metropolis, lahan-lahan hijau berubah menjadi lahan yang dapat dimanfaatkan untuk keperluan lain seperti perumahan ataupun kepentingan bisnis. Potensi-potensi alam yang tadinya sangat banyak kini kian berkurang.

Dengan kondisi yang demikian, maka salah satu usaha yang akan dilakukan dan dapat menjadi sebuah destinasi wisata adalah dengan membangun Vivarium. Vivarium sendiri berasal dari kata vivaria (tempat kehidupan) dan arium (wadah tertutup). Hal ini dikarenakan untuk mengembalikan sebuah ekosistem alami masuk ke tengah kota merupakan hal yang cukup sulit. Ide Vivarium sendiri berarti memasukan ekosistem ke dalam suatu wadah yang tertutup sehingga dapat dibawa masuk ke tengah kota.

\section{KAJIAN LITERATUR}

Vivarium mencakup Aquarium (aqua: air, arium: wadah tertutup), Terrarium (terra: bumi/tanah, arium: wadah tertutup), Paludarium (palus: rawa, arium: wadah tertutup), dan Riparium (ripa: sungai, arium: wadah tertutup). Aquarium merupakan sebuah wadah yang berisikan ekosistem air. Ekosistem air tawar, air laut, muara, pantai, terumbu karang, laut dalam, dan lamun(tumbuhan berbunga di laut) merupakan contoh dari ekosistem air yang masuk dalam kategori aquarium. Terrarium merupakan wadah yang berisikan ekosistem tanah atau bumi seperti hutan hujan tropis, sabana, padang rumput, gurun, hutan gugur, taiga, tundra, dan gua. Sedangkan Paludarium berisikan ekosistem rawa dan Riparium berisikan ekosistem sungai.

Dalam proyek ini ekosistem yang berusaha untuk dikembalikan adalah ekositem rawa sebagai ekosistem alami yang pernah ada di Jakarta dan sekarang telah mengalami perubahan menjadi ekosistem kota. Pengembalian ekosistem ini tentu bukan hal yang mudah untuk dilakukan. Rawa merupakan bagian permukaan pada bumi yang selalu basah karena tergenang oleh air dan juga karena kekurangan aliran, atau juga bagian bumi yang lebih rendah dari daerah di sekitarnya.

Rawa, menurut ilmu geografi, memiliki ciri-ciri :

- Air yang asam dan berwarna coklat, bahkan sampai kehitam- hitaman.

- Berdasarkan tempatnya, rawa- rawa ada yang terdapat di area pedalaman daratan dan atau di sekitar pantai.

- Air rawa yang berada di sekitar pantai dipengaruhi oleh pasang surutnya air laut. Ketika air laut sedang pasang, maka permukaan rawa akan tergenang, sementara ketika air laut surut, daerah ini akan nampak kering bahkan tidak ada air sama sekali.

- Rawa yang berada di tepian pantai banyak ditumbuhi oleh pohon- pohon bakau, sementara rawa yang berada di pedalaman banyak ditumbuhi oleh pohon- pohon palem atau nipah.

Jenis-jenis Ekosistem Rawa menurut dosenbiologi.com:

- Rawa air asin

Ekosistem rawa yang memliki air asin terletak di tepi pantai yang terkena pengaruh pasang atau surut air laut. Sehingga, air asin yang ada pada pantai inilah yang membuat air di ekosistem rawa itu menjadi asin. Pada ekosistem ini banyak terdapat organisme uniseluler. 
- Rawa air payau

Payau merupakan pencampuran sama rata antara air asin dengan air tawar. Ekosistem rawa yang berisi air payau ini berada di sekitar muara sungai, dan dipengaruhi oleh air dari laut yang akan mengkontaminasi air di rawa tersebut. Dalam ekosistem ini terdapat hewan vertebrata dan invertebrata.

- Rawa air tawar

Air tawar pada ekosistem ini tidak terkontaminasi dengan air dari sumber lain. Ekosistem air tawar ini tidak mengalami pergantian air dan tidak bertambah atau berkurang karna pengaruh air dari sumber lain. Ekosistem ini terdapat pada aliranaliran sungai besar yang biasanya terdapat pada hutan-hutan yang masih jarang dijamah oleh manusia. Dalam ekosistem ini terdapat hewan amfibi.

Manfaat Ekosistem Rawa bagi kehidupan manusia menurut manfaat.co.id adalah :

1. Sebagai sumber mata air dan juga sumber air. Namun, ada beberapa rawa yang airnya tidak layak dikonsumsi untuk manusia.

2. Melindungi ekosistem bagi daerah pesisir. Pada ekosistem pantai yang merupakan salah satu perbatasan antara daratan dan juga laut, rawa dapat berfungsi sebagai penyangga dan juga pencegah terjadinya erosi karena air laut.

3. Dapat melindungi lingkungan dari banjir. Dengan adanya rawa, maka air yang berlebihan debitnya dapat tertampung sementara dan juga dapat terserap pada rawa-rawa.

4. Sebagai sumber mata pencaharian. Daerah sekitar rawa memiliki banyak pohonpohon kecil yang dapat diambil kayunya. Selain itu, hewan yang hidup di sekitar rawa, dapat diburu dan dijual.

5. Sebagai lahan untuk membuat daratan. Reklamasi merupakan proses pemadatan daerah seperti rawa menjadi daratan yang padat dan stabil, sehingga dapat dibuat menjadi lahan pemukiman baru.

6. Baik untuk memperbaiki kualitas udara. Daerah rawa memiliki banyak tanamantanaman yang baik untuk memperbaiki kualitas udara lingkungan. Hal ini disebabkan daerah rawa memiliki beragam flora yang melakukan fotosintesis, sehingga dapat melepas oksigen ke udara.

7. Menjadi sumber pangan. Beberapa flora dan fauna yang ada pada daerah rawa dapat dimanfaatkan sebagai bahan pangan.

8. Tumbuhan rawa sebagai bahan bakar. Biogas dapat dibuat dengan menggunakan tanaman, salah satunya adalah tanaman eceng gondok yang dapat diperoleh dari daerah rawa-rawa.

9. Sebagai lokasi wisata. Banyaknya keanekaragaman hayati yang terdapat di daerah rawa menjadi menarik untuk dijadikan lokasi wisata.

10. Lokasi untuk mendapatkan ketenangan dan juga meditasi. Lokasi rawa merupakan salah satu lokasi yang tenang dan alami. Hal ini dapat dimanfaatkan untuk berbagai macam hal, salah satunya menghilangkan stress.

11. Dapat menggemburkan tanah. Tanah rawa dapat dimanfaatkan untuk menjadi media tanam yang baik karena dapat menyuburkan tanaman.

12. Sebagai pembudidayaan ikan. Beberapa jenis ikan dapat hidup di daerah rawa. Maka lahan rawa dapat dimanfaatkan sebagai salah satu media untuk peternakan dan pembudidayaan ikan 


\section{METODE}

Metode yang digunakan dalam merancang proyek ini diawali dengan kajian literatur, menetapkan rumusan permasalahan, menentukan program aktivitas, menganalisis perkotaan untuk menentukan lokasi dan analisis untuk menentukan tapak yang tepat kemudian menganalisa lingkungan sekitar tapak serta potensi yang dimiliki tapak untuk menyusun konsep perancangan tapak seperti konsep sirkulasi, zoning, dan gubahan massa.

\section{DISKUSI DAN HASIL \\ Konsep Perancangan}

Proyek Vivarium ini berlokasi di Jl. Muara Baru Raya, Penjaringan, Jakarta Utara, dan berada di dalam jalur wisata Jakarta Utara. Aktivitas yang ada di dalam proyek ini dibagi menjadi aktivitas utama, penunjang, dan servis. Aktivitas utama dari proyek ini adalah Paludarium yang berisikan wisata ekosistem rawa yang akan membawa pengunjung masuk ke dalam ekosistem rawa buatan. Dengan demikian maka pengunjung dapat melakukan pengamatan lebih dekat dan lebih mengenal tumbuhan serta hewan yang ada di dalamnya. Selain ekosistem rawa, di dalamnya akan di masukan juga ekosistem pantai buatan yang bertujuan untuk menyesuaikan kondisi rawa buatan dengan rawa air asin di tempat alaminya. Dengan demikian hewan dan tumbuhan akan hidup seperti di habitat aslinya dan pengunjung mendapatkan pengalaman ruang yang baru. Pengunjung akan diberikan kesempatan untuk berinteraksi langsung dengan mahluk hidup dalam ekosistem buatan ini. Interaksi ini juga dapat dilakukan sesama pengunjung untuk menikmati ekosistem buatan ini.

Aktivitas yang akan menunjang proyek ini adalah kuliner sehingga pengunjung dapat menikmati suasana makan di tengah ekosistem rawa buatan ini. Selain itu pengunjung juga akan mendapatkan edukasi tentang ekosistem yang ada di Jakarta serta cara untuk merawat dan melestarikannya serta manfaat yang didapat apabila menjaga keseimbangan ekosistem dan juga dampak buruk bila mengabaikannya. Pertunjukan hewan rawa juga dapat dinikmati pengunjung sehingga pengunjung dapat lebih mengenal kehidupan di dalam rawa. Aktivitas penunjang lainnya seperti kebutuhan servis juga akan ditambahkan dalam proyek ini. Tujuannya adalah untuk pemeliharaan dan perawatan ekosistem buatan agar kondisinya tetap mirip dengan habitat aslinya sehingga tumbuhan dan hewan yang ada di dalamnya dapat hidup dengan baik dan bertumbuh.

\section{Program Ruang}

Tabel 1. Program Ruang

\begin{tabular}{lc}
\hline \multicolumn{1}{c}{ Nama Ruang } & Luasan $\mathbf{( m}^{\mathbf{2}} \mathbf{)}$ \\
\hline Lobby & 180 \\
\hline Hall & 332 \\
\hline $\begin{array}{l}\text { Observasi Rawa } \\
\text { dan Pantai }\end{array}$ & 2895 \\
\hline $\begin{array}{l}\text { Interaksi Rawa } \\
\text { dan Pantai }\end{array}$ & 3044 \\
\hline Restoran & 1557 \\
\hline Cafe & 302 \\
\hline $\begin{array}{l}\text { Ruang } \\
\text { Pertunjukan }\end{array}$ & 615 \\
\hline $\begin{array}{l}\text { Karantina dan } \\
\text { Laboratorium }\end{array}$ & 414 \\
\hline
\end{tabular}

\begin{tabular}{lc}
\hline \multicolumn{1}{c}{ Nama Ruang } & Luasan $\left(\mathbf{m}^{\mathbf{2}}\right)$ \\
\hline Toko Souvenir & 246 \\
\hline Ruang Direktur & 20 \\
\hline Ruang Karyawan & 200 \\
\hline Ruang Arsip & 12 \\
\hline Ruang Pertemuan & 30 \\
\hline Ruang Elektrikal & 400 \\
\hline Ruang Mekanikal & 375 \\
\hline Ruang Tunggu & 100 \\
\hline Parkir Motor & 1019 \\
\hline Parkir Mobil & 5453 \\
\hline Parkir Bus & $\mathbf{2 8 8}$ \\
\hline \multicolumn{1}{c}{ Total } & $\mathbf{1 7 8 9 3}$
\end{tabular}

Sumber: Olahan penulis, 2018 


\section{Proses Desain}

Tahapan perancangan proyek ini dimulai dengan proses analisis tapak meliputi analisis kontur tapak, akses menuju ke tapak, analisis terhadap arah edar matahari serta angin.

Gambar 1. Analisis Kontur

Sumber: Olahan penulis, 2018
Gambar 2. Analisis Arah Edar Matahari dan Angin Sumber: Olahan penulis, 2018

Kontur tapak yang memiliki kemiringan tertentu yang dimanfaatkan untuk membagi zona rawa dan pantai (lih. Gambar 1). Perlindungan terhadap radiasi matahari pada bagian-bagian tertentu dapat disiasati dengan menanam pohon peneduh pada bagian yang berpotensi terkena sinar matahari yang berlebih. Tapak berada di dekat laut, maka angin yang bertiup dari arah laut dapat dialirkan ke dalam tapak dengan menggunakan bangunan sebagai media aliran angin (lih. Gambar 2).

\section{Gambar 3. Analisis Akses Menuju Tapak} Sumber: Olahan penulis, 2018

\section{Gambar 4. Analisis Zoning dalam Tapak}

Sumber: Olahan penulis, 2018

Tapak dapat diakses melalui jalan utama yang mengelilingi tapak. Sehingga bangunan penerima akan diletakan berdekatan dengan akses dari jalan yang paling mudah pencapaiannya (lih. Gambar 3). Dari analisis yang telah dilakukan, maka dapat disimpulkan bahwa pembagian zona dalam tapak dibagi menjadi zona rawa dan zona pantai yang dibatasi oleh bangunan. Hubungan ruang yang terbentuk dimulai dari bagian penerima yang terhubung dengan aktivitas utama (lih. Gambar 4). Aktivitas utama akan berhubungan langsung dengan aktivitas penunjang di sekitarnya. Dengan kata lain, aktivitas utama merupakan pusat dari proyek ini. Kemudian, pembedaan zona rawa dan zona pantai dimanfaatkan untuk membagi zona flora dan fauna khas rawa pantai. Karnanya, terdapat 4 massa yang akan terhubung dengan sirkulasi pengunjung yang dialirkan di dalam proyek ini. 


\section{Keterangan:}

A. Hubungan Ruang

B. Pembagian Zoning

C. Sirkulasi Penghubung Massa

D. Akses Tapak

E. Zoning Hewan

F. Gubahan Massa

Informasi Lahan:

$\begin{array}{ll}\text { Luas lahan } & : 13500 \mathrm{~m}^{2} \\ \text { KDB } & : 50 \%\left(6.750 \mathrm{~m}^{2}\right) \\ \text { KLB } & : 2\left(27.000 \mathrm{~m}^{2}\right) \\ \text { KDH } & : 30 \%\left(4.050 \mathrm{~m}^{2}\right) \\ \text { KTB } & : 55 \%\left(7.425 \mathrm{~m}^{2}\right) \\ \text { KB } & : 4\end{array}$

Gambar 5. Proses Gubahan Massa dan Informasi Lahan Sumber: Olahan penulis, 2018 


\section{Bentuk Ruang}

Pada massa penerima, ruang akan dibuat dalam skala manusia sehingga pengunjung akan merasakan suasana indoor. Pada massa penunjang, ruang akan dibuat terbuka sehingga suasana outdoor yang akan dirasakan. Selain itu pengunjung juga tidak akan melihat keluar tapak dikarenakan penanaman pohon-pohon di sekitar tapak yang akan membatasi pengelihatan pengunjung.

Pada massa penunjang, ruang disesuaikan dengan kebutuhannya. Pada bagian pertunjukan, ruang dibentuk menyerupai teater agar pengunjung dapat menikmati pertunjukan. Pada bagian karantina, ruang dibuat terisolasi sehingga tidak akan terjadi kontak antara hewan maupun tumbuhan yang sakit dengan yang sehat (Gambar 6).

Gambar 6. Gambar Potongan Bangunan

Sumber: Olahan penulis, 2018

\section{Hasil Desain}

Proyek ini dirancang berdasarkan dari pengalaman ruang pengunjung. Pengalaman ruang ini dimulai dari masuk hingga keluar membentuk sebuah sirkulasi yang mengalir. Selain itu, bangunan dibuat melayang agar rawa buatan mendapatkan luasan yang maksimal.

Lengkungan-lengkungan yang terbentuk, terinspirasi dari bentukan air yang mengalir. Tujuan dari bentuk ini adalah tidak membatasi sudut pandang pangunjung untuk dapat melihat ke luar maupun ke dalam bangunan. Pada lantai dasar ini, pengunjung pertama diarahkan menuju ke loket dan kemudian melewati ruang pertunjukan indoor. Dalam ruang ini, pengunjung akan dikenalkan dengan ekosistem rawa yang baik dan sehat. Kemudian pengunjung akan diedukasi mengenai kondisi ekosistem rawa khususnya di Jakarta. Setelah itu pengunjung akan dibawa ke ruang outdoor dan berinteraksi secara langsung dengan hewan dan tumbuhan khas rawa. Selain itu pengunjung juga akan diajak ke ruang pertunjukan dimana hewan khas rawa akan menunjukan talentanya. Terdapat juga diorama pada bagian indoor yang berisikan tentang perjalanan rawa serta fakta-fakta maupun mitos-mitos mengenai rawa. Selain itu sebagian dari rawa terlihat juga di dalam ruang indoor.

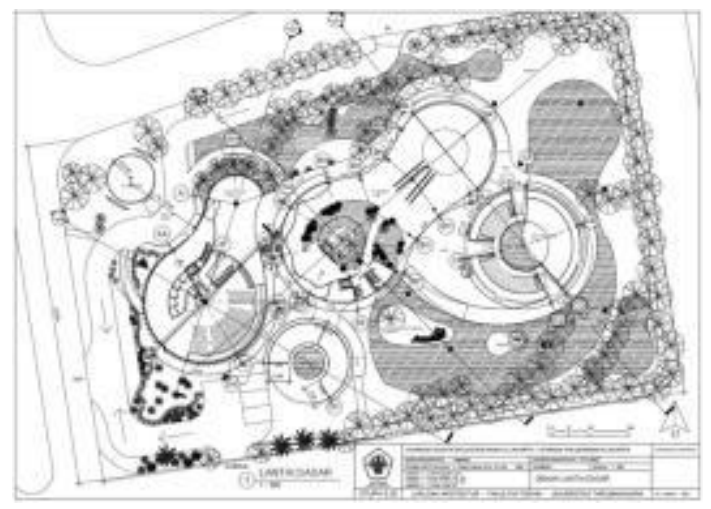

Gambar 7. Denah Lantai Dasar

Sumber: Olahan penulis, 2018

Gambar 8. Denah Lantai Satu

Sumber: Olahan penulis, 2018
Gambar 9. Denah Lantai Dua

Sumber: Olahan penulis, 2018

Pada lantai satu, pengunjung dapat mengobservasi rawa dari ketinggian 8 meter hingga 5 meter diatas rawa. Dari ketinggian ini, maka pengunjung dapat melihat bagaimana interaksi hewan dengan lingkungan habitatnya serta perilakunya berinteraksi dengan manusia. Selain itu pengunjung juga dapat berkunjung ke café dan tetap mendapatkan pemandangan ke arah rawa. Lekukan yang terjadi pada lantai ini bertujuan untuk memaksimalkan pandangan pengunjung ke dua sisi. Selain itu terdapat lantai kaca dengan ketinggian 5 meter diatas hewan 
buas agar pengunjung dapat melihat hewan lebih dekat tanpa merasakan bahaya dari hewan buas tersebut.

Pada lantai dua, pengunjung dapat menikmati santapan di restoran yang bertemakan rawa. Tidak ada hewan yang lalu lalang pada lantai ini (Gambar 9). Hanya terdapat tumbuhan peneduh agar menghindari pengunjung dari sinar matahari langsung. Selain itu terdapat juga panggung untuk hiburan mengiringi santapan. Pembatas yang digunakan pada lantai ini berupa tanaman yang dimanfaatkan juga sebagai sandaran bangku pengunjung.

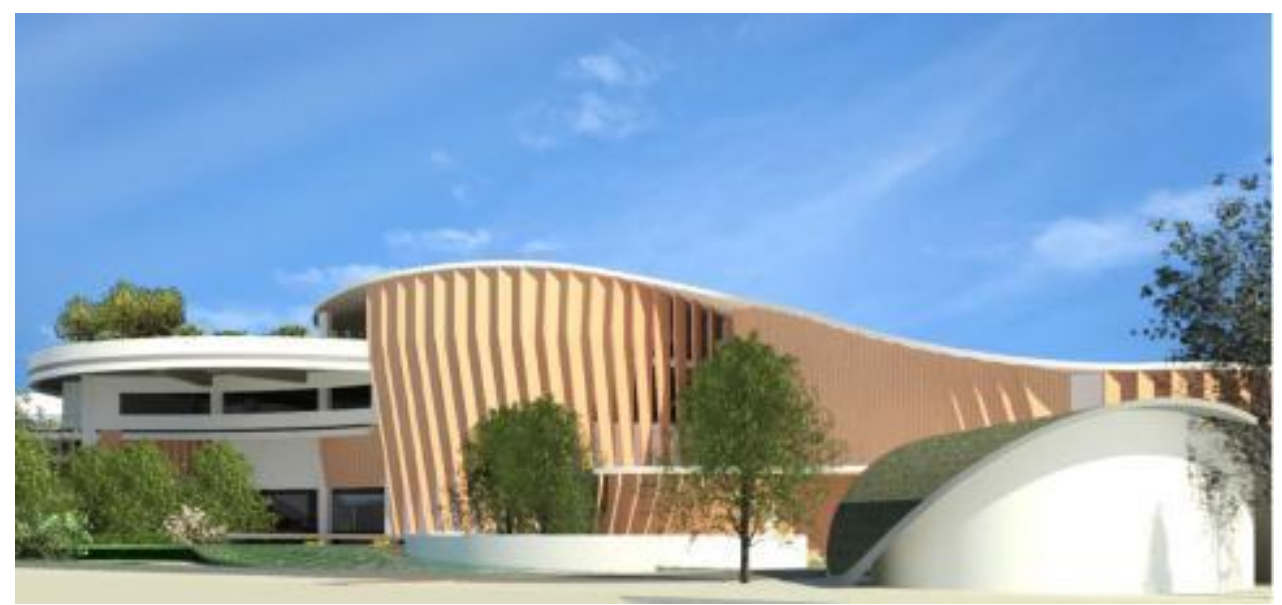

Gambar 10. Gambar Eksterior Bangunan

Sumber: Olahan penulis, 2018

Pada bagian eksterior digunakan sirip dengan bahan beton yang dengan finishing kayu. Tujuan dari sirip ini adalah untuk menggantikan fungsi talang. Selain itu bangunan yang menghadap matahari barat akan menghalau sinar matahari langsung. Selain itu sirip ini juga menjadi kekuatan untuk ikut menopang atap.

\section{Gambar 11. Gambar Interior Bangunan}

Sumber: Olahan penulis, 2018

Pada bagian interaksi rawa, ruang dibuat terbuka dengan tujuan mendekatkan pengunjung dengan ekosistem rawa. Pada bagian ini, bangunan dibuat dengan suasana outdoor dan terbuka agar iklim alami dari rawa buatan ini terasa oleh pengunjung.

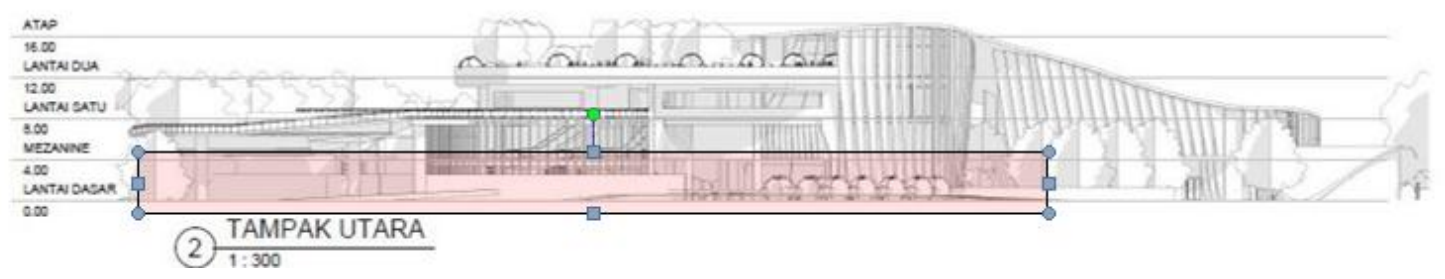




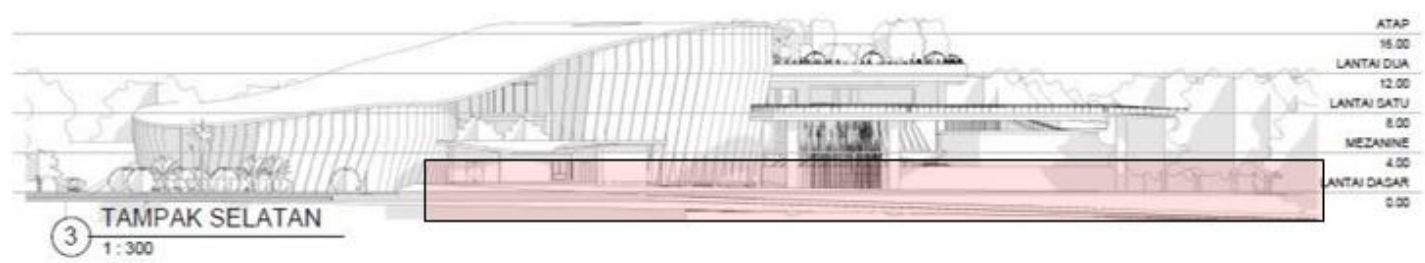

Gambar 12. Gambar Tampak Bangunan

Sumber: Olahan penulis, 2018

Pada bagian tampak dapat dilihat bahwa bangunan dibuat melayang dengan tujuan memaksimalkan luas rawa yang berada di bawahnya. Selain itu, rawa dapat dengan mudah dibawa masuk ke bagian dalam bangunan. 


\section{Gambar 13. Gambar Potongan Perspektif}

Sumber: Olahan penulis, 2018

Pada gambar diatas dapat terlihat jelas bahwa rawa berada di bawah bangunan dan bangunan melayang diatas rawa. Dengan demikian, maka pemanfaatan lahan bagi rawa menjadi maksimal dan rawa dapat dinikmati dari banyak sisi. Dari sisi outdoor, indoor, bahkan melayang diatas rawa dari ketinggiam 1 meter, 5 meter, dan 8 meter.

\section{KESIMPULAN DAN SARAN}

Ekosistem rawa harus dijaga kelestariannya. Namun, untuk mengembalikan ekosistem rawa bukan merupakan hal yang mudah. Maka dari itu, langkah awal yang dapat dilakukan adalah dengan menghadirkan kembali ekosistem rawa dan mengajak mengedukasi dan memperkenalkan ekosistem rawa serta manfaatnya kepada masyarakat.

Usaha menghadirkan kembali ekosistem rawa di Jakarta adalah dengan menggunakan Vivarium atau kehidupan dalam suatu wadah. Bentuk dari Vivarium yang digunakan adalah Paludarium atau ekosistem rawa dalam suatu wadah. Ekosistem rawa yang akan dihadirkan kembali adalah ekosistem rawa air asin. Lokasi yang sesuai dengan proyek ini adalah Jakarta Utara yang dikenal dengan rawa-rawa.

Dalam proyek ini, pengunjung akan diajak merasakan pengalaman berjalan di tengah rawa air asin buatan dan mengenal flora serta fauna khas rawa air asin. Selain itu, pengunjung dapat menikmati ekosistem rawa air asin buatan lebih dari satu sisi pandang dan dapat menikmati kuliner di dalam ekosistem rawa air asin buatan ini. Pengunjung akan diajak untuk mengenal ekosistem rawa pantai lebih dekat dan berinteraksi secara langsung.

Untuk merancang proyek seperti vivarium ini maka sebaiknya menggunakan pendekatan pengalaman ruang yang akan diberikan bagi pengunjung. Dengan mengarahkan pengunjung melewati perjalanan di dalam proyek, maka hubungan ruang yang ingin dibuat menjadi lebih jelas. Menghadirkan kembali ekosistem alami yang pernah ada di DKI Jakarta sebagai bentuk usaha untuk menjaga kelestarian dan keseimbangan ekosistem yang berada di Jakarta, khususnya ekosistem rawa yang merupakan ekosistem alami di Jakarta yang sudah berubah fungsi dengan membangun Vivarium.

\section{UCAPAN TERIMA KASIH}

Penulis mengucapkan terima kasih kepad para dosen pembimbing yang sudah mendampingi dan membimbing dari tahap awal hingga tahap akhir Tugas akhir termasuk dalam penyusunan artikel Jurnal STUPA.

\section{REFERENSI}

Specht, Jan. (2014). Architectural Tourism. Munich : Springer Gabler

Frick, Heinz, dan Tri Hesti Mulyani. (2006). Arsitektur Ekologis. Yogyakarta : Kanisius

https://ilmugeografi.com/ilmu-bumi/hutan/rawa-rawa

https://dosenbiologi.com/lingkungan/ekosistem-rawa

https://manfaat.co.id/manfaat-rawa-bagi-kehidupan-manusia

https://www.archdaily.com

https://tataruang.jakarta.go.id

https://www.google.co.id/maps 